\title{
ESTUDIO COMPARADO DEL DELITO DE FALSEDAD DOCUMENTAL EN EL DERECHO HISPÁNICO E INGLÉS (SIGLOS XVI-XVIII)
}

\author{
THE CRIME OF FORGERY IN THE HISPANIC AND ENGLISH LAW \\ FROM THE 16TH TO THE 18TH CENTURIES. A COMPARATIVE \\ STUDY
}

\section{Luis IGLESIAS RÁBADE*}

RESUMEN: Este estudio examina y compara la regulación del delito de falsedad documental en las fuentes normativas y doctrinales hispánica e inglesa en los siglos XVI-XVIII, incluyendo los antecedentes medievales. Se estudia el origen y desarrollo de las notas distintivas del delito y del bien jurídico protegido, así como la configuración de su ámbito subjetivo y material. Se resaltan aquellas diferencias más visibles relativas a la calificación del delito en los ordenamientos hispánicos e ingleses, prestando especial atención a la evolución en la tipología de penas y del régimen sancionador. En el ámbito de la práctica forense, se presentan numerosos ejemplos de las Ejecutorias de la Real Audiencia y Chancillería de Valladolid y de juicios en el Tribunal Penal Central de Londres.

Palabras clave: Falsedad documental, Edad Moderna, Hispánico, Inglés. Estudio comparado.

ABSTRACT: This study examines and compares the indictable offense of forgery in the legal sources of Hispanic and Anglo-Saxon territories from the 15th to the 18th centuries, including medieval legal background. An attempt is given to determine the origin and development of its distinguishing notes and the interest legally protected, as well as its subject-matter and the offenders' responsibility. Special emphasis is given to the development in the typology of punishment in English and Hispanic territories, providing numerous examples from the Ejecutorias of the Real Audiencia y Chancilleria de Valladolid and the trials held at London's central criminal court from 1674 to 1830.

Keywords: Forgery, Modern Period, Hispanic, English. Comparative study.

\section{INTRODUCCIÓN}

En este estudio comparativo del delito de falsedad documental en el derecho hispánico e inglés (siglos XVI-XVIII) se configura en torno a dos premisas. Se parte de la presunción de similitud que actúa como tertium comparationis, en tanto en cuanto se prevé que el documento tiene la misma función a efectos de prueba judicial en los territorios

Catedrático de la Universidad de Santiago de Compostela. Dirección postal: Avda. Dr. Ángel Echeverri, s/n. Campus sur, 15782 Santiago de Compostela (España). Dirección electrónica: luis.iglesias.rabade@usc.es 
hispánico e inglés. Se presume, asimismo, que existe una divergente configuración del delito porque la percepción social del mismo es también diferente. Por tanto, siguiendo las técnicas y la metodología del derecho comparado, este estudio trata de descubrir e interpretar las diferencias y similitudes en el ámbito normativo y doctrinal de este instituto jurídico-penal atendiendo al contexto cultural, religioso y socioeconómico de los dos sistemas jurídicos objeto de comparación.

El examen de las Ejecutorias de la Real Audiencia y Chancillería de Valladolid y de las decisiones judiciales del Tribunal Penal Central de Londres en relación a este delito, nos permitirá obtener información comparativa en diferentes dominios del documento en el tráfico jurídico y en el ámbito procesal.

\section{NOTAS DISTINTIVAS DEL DELITO: ORIGEN Y DESARROLLO}

En el ámbito normativo, las fuentes del Bajomedievo hispánico integran, en general, dos elementos básicos constitutivos del delito de falsedad documental que figuraban en el Liber Iudiciorum: un acto consciente (que puede adoptar múltiples formas de ejecución ${ }^{1}$ ) de "mudamiento" de la verdad, realizado con dolo en beneficio propio o por malquerencia. Así pues, el falsum jurídico -documental- no se perfecciona con la imitación de la realidad, sino con la conducta dolosa que la transforma, bien sea alterándola, contradiciéndola o destruyéndola. Siendo así, todo acto de falsificación dolosa requeriría de la concurrencia de un proceso cognitivo del autor material o su inductor capaz de reconocer que su conducta es contraria a derecho o a las buenas costumbres, junto a un proceso volitivo o voluntad inequívoca de consumar dicha acción bien sea de forma directa (dolo directo), indirecta (dolo eventual).

Esta concepción formalista del delito de falsedad documental asentada en el "mudamiento" doloso de la verdad arranca de la doctrina jurisprudencial de los jurisconsultos del Bajo Imperio Romano ${ }^{2}$. Sin embargo, este diseño normativo se transforma con las aportaciones doctrinales de glosadores y comentaristas de la Escuela de Bolonia (particularmente, Bartolo de Sassoferrato) en el Bajomedievo y por criminalistas como Farinacio en la era Moderna temprana, quien sintetizó las notas distintivas del crimen falsi en la definición falsitas est veritatis mutatio dolosae et alterius prejuditium facta ${ }^{3}$.

Por tanto, con estos precedentes, la inveracidad punible en la era Moderna requiere también de la existencia de una voluntad consciente de crear un instrumento inveraz o alterar el documento auténtico causando un perjuicio ajeno y quebrando la confianza en la declaración documentada. Según Antonio de la Peña, la puesta en riesgo de perjuicio o

Lib., 7, 5, 2.

2 Las notas distintivas del crimen falsi de la Lex Cornelia se desarrrollaron a través de los senadoconsultos de la época del Principado [Dig. 48, 10 pr. (sc. Liboniano); Dig.48, 10, 1 (sc. Liciniano, 16 d.C); Ulpiano, Coll. 8.7.2 (sc. Messaliano, 20 d.C.) y Ulpiano, Coll. 8, 7, 3 (sc. Geminiano, 29 d.C.) y su interpretación jurisprudencial por los jurisconsultos del Bajo Imperio hacia el s. III d. C., principalmente de Paulo (Sent. 4, 7, 2), Ulpiano (Dig. 48, 10, 9) y Marciano (Dig. 48, 10. pr., 1, y 2). Para un análisis en detalle del objeto material de las falsedades en Roma, véase Mayer Lux y Vera Vega (2015) pp. 329-334.

3 Farinaccio (1595) Quaestio 150. 
daño ajeno integraría también todos los elementos de la antijuridicidad, aunque su infractor no sería sancionado con pena ordinaria, sino "extraordinaria según albedrío del juez" dado que el juzgador tendría que evaluar las posibilidades de un riesgo cierto, probable o incierto. Esta nota distintiva (el perjuicio ajeno) será determinante para la imputabilidad en la doctrina de juristas y prácticos del derecho hispánico en la era Moderna 5 .

\section{EVOLUCIÓN DEL BIEN JURÍDICO PROTEGIDO}

En el pensamiento jurídico de la tradición hispánica predominó la concepción, heredada de la doctrina italiana, de que la falsedad documental es un tipo de ilícito punible que atenta al tráfico jurídico. Por tanto, el bien jurídico tutelado debe apreciarse en relación a la función específica que el documento representa en el tráfico jurídico, bien sea como medio de prueba, como signo de autenticación o como instrumento de garantía ${ }^{6}$. De ahí que la falsificación de un documento genuino, que no tenga en su origen función acreditativa de veracidad, no irroga conducta punible.

En el S. XVIII se impuso en la doctrina de la tradición romanística la noción de que el documento falso quebranta la confianza en la declaración documentada, lo que vino a redefinirse como una transgresión de la fe pública ${ }^{7}$. Las acciones falsarias que afectan a instrumentos documentales que transitan en el tráfico jurídico agreden directamente la confianza depositada por la comunidad en la veracidad intrínseca del documento destinado a ser portador de derechos y obligaciones. No obstante, esta configuración de la falsedad documental como quiebra de la fe pública -o de la veracidad inherente del documentosupondría admitir que el bien jurídico tutelado es la verdad misma, como si, en realidad, existiese un derecho a la verdad, que es tanto como afirmar que toda mentira -documentada o no-, sería punible ${ }^{8}$.

Peña (1935) vol. XVIII, No 70, p. 185: “De falso ninguno puede ser castigado sino cuando por falsedad cometida se siguiere algún daño a alguno o se pudiere seguir, pues no siguiéndose daño aunque la falsedad fuere con dolo cometida, no será castigado en la pena ordinaria pero ha de dársele pena extraordinaria según albedrío del juez”. También Alejandre (1972) p. 159.

Vela y Acuña (1603) Cap. 10, no 3: “... licet falsitas debeat esse nociva ut poena falsi locum habeat"; SESSE (1615) vol. I, Decisio 109, no 11: "falsitas ad hoc, ut puniatur debet nocere, vel posse nocere" (cito por el Sumarium de la citada Decisio). Mattheu y Sanz (1686) Controv. 5, núm. 28: "Dolus comprobatur es mutatione veritatis anima capiendi lucrum cum jactura aliena”. En referencia al notario, señala López 1844 en Glosa a Part. 7, 7, 1, p. 115: "si el documento fuese nulo por defecto intrínseco del mismo, de suerte que no pueda causar perjuicio á tercero; entónces no debe ser castigado el Escribano (...) por el contrario si del instrumento pudiera resultar perjuicio á alguno (...) entonces se castigaria al Escribano por el crimen de falsedad". También en la Modernidad tardía Álvarez Posadilla (1833), pp. 442-443: “ó la falsedad es sustancial ó accidental: falsedad sustancial es faltar á la verdad en lo sustancial del instrumento, como hacer un instrumento en nombre de uno que no lo ha otorgado, ó poniendo cosa diversa en la sustancia de lo que el otorgante ha dicho: accidental es cuando el otorgante ha otorgado el instrumento, y ha dicho lo que en él pone el escribano; pero pone la fecha ó día distinto del en que se otorga, sin que de ellos se siga perjuicios á tercero". Para más concreción sobre las notas distintivas de dolo y perjuicio ajeno con referencias a la doctrina jurídica, también AlejANDRE (1972) pp. 159-160. A este autor me remito para no "reproducir" las fuentes doctrinales.

FARINACCIO (1595) Quaestio 150.

FiLANGIERI (1796) vol. IV, pp. 304 y ss.

Binding (1904) vol. II, pp. 120 y ss. 
En la Modernidad tardía se da otro enfoque a la configuración jurídica de este delito redefiniendo el interés tutelado en función de la finalidad que el transgresor se propone para incorporar un documento falso al tráfico jurídico. En puridad, la finalidad no es otra que la de utilizar un medio instrumental para lesionar otros intereses jurídicos tutelados, de modo que no se castiga realmente el quebrantamiento de la fe pública o veracidad del documento -pues el bien jurídico protegido no es el documento mismo-, sino aquellos intereses que son objeto de ataque por dicha falsedad. Estaríamos ante un delito de carácter pluriofensivo9. Sin embargo, esta interpretación de que la falsedad documental es un delito pluriofensivo supondría ampliar su ámbito objetivo en función de que el ilícito afectase, por ejemplo, al honor o al patrimonio de la persona o personas que sufren las consecuencias de la falsedad documental, lo que no tendría justificación, toda vez que estos bienes jurídicos tutelados ya han tenido históricamente su ubicación en los textos normativos como tipos diferenciados de la falsedad documental.

En la tradición anglosajona, el delito de falsificación de documento público se considera una quiebra de la "lealtad" al monarca, al señor feudal o a la autoridad administrativa o judicial, de ahí que se le integre en la categoría de los delitos de traición. Por su parte, la falsificación de documento privado, como se verá en este trabajo, no adquiere el carácter de crimen falsi hasta el Statute Against Forgers of false Deeds de $1413^{10}$ en el que se refleja que el bien jurídico a proteger es la pureza del proceso judicial. No se penaliza al infractor por su acción fraudulenta dolosa lesiva de intereses ajenos, sino por quebrar la "confianza" del instrumento gráfico en juicio y pervertir el curso normal de la administración de justicia ${ }^{11}$.

\section{3. ÁMBITO MATERIAL DEL DELITO}

(i) Las fuentes normativas locales y territoriales hispánicas del Bajomedievo ${ }^{12}$ y de la era Moderna presentan carencias de acotación del ámbito material del delito, en tanto que bajo la conducta punible de falsedad documental se incluyen ilícitos muy heterogéneos. El Derecho castellano bajomedieval es una buena muestra de ello; por ejemplo, el Fuero Real recupera la enumeración abierta de acciones de comisión del delito prácticamente transcritas de Paulo ${ }^{13}$ - "mudando, tolliendo, ennadiendo, desatando, camiando el dia o el mes, o la era" - dejando incluso el inventario abierto con la expresión "por otra guisa cualquier"14. El Espéculo describe también un catálogo no acotado de las modalidades de comisión del

\footnotetext{
Carnelutti (1935) pág. 2.

10 Statute 1 Henry V. c. 3.

11 Pollock y Maitland reseñaron: "it is not the making of a false document to intent to defraud; rather it is the reliance on a false document in a court of law" (Pollock y MaITLAND (1968), vol. II. p. 540). Vid. también HoldsWorTH (1903-1966) vol. III, p. 400.

12 Para una mayor concreción de fuentes medievales, véase Alejandre (1972) pp. 134 y ss. y MaYer LuX Y Vera Vega (2015) pp. 334-338.

13 Es transgresor el que scripserit, signaverit, resignaverit (PAULO, Sent., 4, 7, 1) o scriberet, scripserit, signare, interlinere (Dig. 48, 10 pr.) dejando también abierto el tipo de instrumentos quirográficos objeto de posible falsificación bajo la expresión aliud instrumentum.

$14 \quad F R ., 4,12,6$.
} 
delito bajo la fórmula de "quantas maneras pueden ser fechas falsidades en las cartas"15, pues, como se señala en las Partidas, "puédese hacer la falsedad en muchas maneras" ${ }^{16}$. Por eso, en el texto Alfonsino se falsifica cuando se realiza un documento falso, o se adultera la veracidad de su contenido, cuando se modifican los signos externos de su autenticidad -firmas y/o sellos-, cuando se niega la existencia del documento o cuando se hurta, oculta o destruye documento propio ajeno, o se desnaturaliza "de otra manera cualquiera" ${ }^{17}$.

(ii) Por su parte, el delito de falsedad documental en la Inglaterra altomedieval carece de apoyo normativo, pues los códigos de los monarcas anglosajones del Altomedievo no recogen expresamente el delito de falsedad documental, salvo la prescripción relativa a la adulteración del sello regio, que no se contemplaba como un crimen falsi, sino como un acto de traición al rey ${ }^{18}$. Además, el documento privado no representaba todavía un instrumento probatorio o de garantía de derecho, por eso no se incorporó a los autos en sede judicial hasta bien entrado el s. XII. Los derechos y privilegios, los acuerdos entre particulares o clanes, las obligaciones contraídas, etc. se acreditaban en juicio por medio de testigos de parte o cojuradores (oath-helpers).

En el Bajomedievo inglés, tanto en Britton ${ }^{19}$, donde se recoge una compilación de la ley inglesa, como en De Legibus et Consuetudinibus Angliae de Henry de Bracton, solo se prevé el castigo para el falsificador de documento público (carta y sello regio) como un acto de traición a la Corona ${ }^{20}$. Así, el Statute of Treason de 1351 incluye la falsificación del Great and Privy Seal del rey entre los siete tipos de traición contra la Corona ${ }^{21}$. Muestra de ello es el caso juzgado en el King's Bench en 1401 en el que el reo acusado de Forgery of the king's commission and misusing the king's seal es condenado a la pena de muerte agravada (eviscerado y ahorcado ${ }^{22}$ ). También la falsificación de documento con sello de un noble por parte de vasallo se calificaba como un delito de traición menor hasta finales del s. XII, sancionado con pena de picota o capital, según las circunstancias agravantes ${ }^{23}$. En cambio, en el s. XIV la falsificación de otro tipo de documento público -administrativo o judicial-ve moderada su calificación al reputarse como felonía sancionada con pena corporal, según la doctrina jurídica de la época ${ }^{24}$.

Es importante reseñar que en la época premoderna inglesa, el delito de falsedad documental era objeto de calificación penal atendiendo a la tipología del documento desnaturalizado, sin tener en cuenta el grado de intervención textual en la calificación del delito,

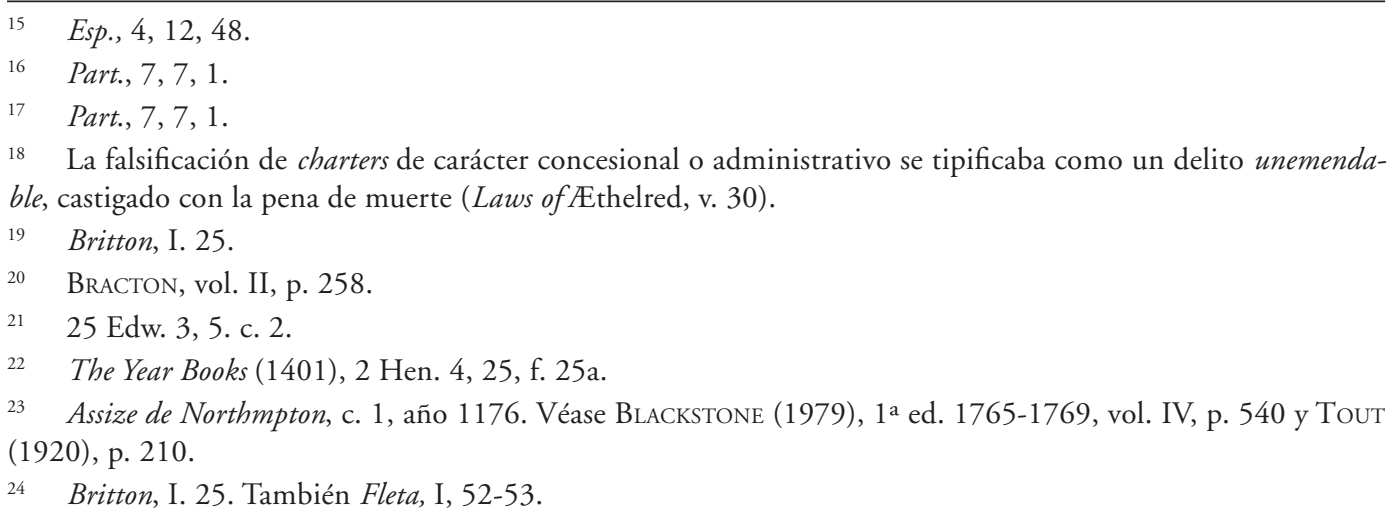


pues las circunstancias concretas de la comisión del acto delictivo quedaba al arbitrio judicial. Siendo así, la falsificación de documento público provisto de sello regio se calificaba como traición y se sancionaba como todos los delitos de traición (pena de muerte agravada), la falsificación de documento público de autoridad judicial o administrativa era una felonía y se castigaba, como todos los actos de felonía, con pena corporal o incluso la pena capital a arbitrio del juez, mientras que la falsificación de documento privado se habría integrado posiblemente entre los delitos menores (misdemeanour) sin apoyo normativo, pese a la presión de los "civilistas" para que se regulase este instituto penal del crimen fals ${ }^{25}$.

(iii) En los territorios hispánicos e ingleses muchas instituciones religiosas desnaturalizaron y "falsificaron" documentos con el fin de atribuirse intereses espurios. Este tipo de "falso histórico", aun siendo objeto de reproche penal, apenas recibía castigo alguno ${ }^{26}$, pues escaso margen le quedaba al juzgador regio para perseguir y castigar el delito de falsedad documental realizada en los scriptoria eclesiásticos. Por una parte, la mayoría de los amanuenses o escribas eran clérigos para los que la autoridad eclesiástica reclamaba su competencia para enjuiciarlos. Por otra parte, el acto material de la falsedad documental se producía en el seno de un scriptorium (entidad), de modo que la responsabilidad del autor material (escriba) se diluía en la propia estructura organizativa de la institución.

\section{EL ÁMBITO SUBJETIVO DEL DELITO}

En el plano subjetivo, tanto en el contexto hispánico e inglés se diferencia históricamente el transgresor cualificado (escribano público ${ }^{27}$, notario, juez, fiscal, etc.) o muy calificado (escribanos de la Casa del Rey) del no cualificado (persona particular, al que los textos normativos hispánicos suelen referirse como "todo home que ficiere carta falsa" 28 , "el que tuviese carta o otra escritura" 29 , "aquells que fan o faran fer cartas falsas" 30 ). Por su parte, la doctrina de la Modernidad temprana ya apuntó algunas de las presunciones para deter-

25 Tanto Glanvill (c. XIV, 7) como Bracton (vol. II, p. 259) sugieren que se regule el "instituto" del crimen falsi. Pero como sostienen Pollock \& Maitland "English law was not ready for this" [POLlock y Maitland (1968) $1^{\text {a }}$ ed. 1895 , vol. II, p. 504

26 Es conocida la actividad documental espuria de los scriptoria de los monasterios ingleses de Westminster [Chaplais (1962) pp. 89 y ss.], de St. Augustine y Christ Church en Canterbury [Southern (1958) pp. 193 y ss.], de Durham [SCAmmell (1956) pp. 300-307], de Glastonbury [Lot (1898) pp. 529 y ss.], de Rochester [Brett (1986) pp. 403-412], del priorato de Wix [Brooke (1962) pp. 45 y ss.] o de las Abadías de Crowland [Tout (1920) pp. 224-225], Evesham [Clanchy (1979) pp. 324-325], Chertsey [Pearsall (2003) p. 6] o de San Albans [Chibnall (1986) pp. 331-346 y Hiatt (2004) p. 32]. La misma práctica se desarrolló en centros monacales hispánicos como los de San Millán de la Cogolla [GarCía de CorTázar (2005) pp. 71 y ss.; y AzCÁrate Aguilar-Amat, et al. 2006, pp. 359 y ss.], Silos [Escalona (2004) pp. 205 y ss., también García de Cortázar (2003) pp. 143 y ss.], Arlanza [Cantera (2013) pp. 63-64 y Escalona (2002) vol. II, pp. 159 y ss.], San Pedro de Cardeña [Peña (2003) pp. 331 y ss.] o Santa María de Valpuesta [Barrau-Dihigo (1900) pp. 274 y ss. e IBÁNEZZ (2003) pp. 151 y ss.], por citar algunos.

27 Sobre los excesos falsificadores de los escribanos, véase Extremera (2005) pp. 465 y ss; Martínez (1962) pp. 328-336; Álvarez-Coca (1987) pp. 555-564 o GonzÁlez de Amezúa (1953) pp. 279 y ss.

$28 F R, 4,12,5$.

29 Part., 7, 7, 1.

30 Fori Regni Valentiae, 9, 3, 5. 
minar los sujetos del delito. Por ejemplo, se presume que el que aporta falso documento en juicio lo ha confeccionado o alterado él mismo o por su mandato ${ }^{31}$, salvo que declare quién lo confeccionó o de quién lo recibió ${ }^{32}$. No obstante, en tanto que sin dolo no hay delito ${ }^{33}$, el que inconscientemente presenta documento falso o ignora que lo es, no se le reputa reproche penal ${ }^{34}$. Igualmente, quien usa documento sustraído se presumirá que la sustracción ha sido realizada por aquel al que beneficie ${ }^{35}$.

Se presume también agravamiento de responsabilidad para el documentante cualificado -fedatario o notario público-, mientras que al que desiste o desvela la acción fraudulenta, se le atenúa ${ }^{36}$, aunque el falsificador que desiste reconociendo su culpabilidad no quedaría inerme de responsabilidad, pues no le habría faltado intención de obtener venta$\mathrm{ja}^{37}$. También se presume menor grado de culpabilidad para el usuario de documento falso con respecto al que lo confecciona ${ }^{38}$. Finalmente, siendo el perjuicio a tercero un elemento constitutivo del delito, la fabricación inducida no consciente de crear un perjuicio no sería punible, pero sí lo sería la actuación del inductor que habría buscado beneficiarse a costa del perjuicio ajeno ${ }^{39}$.

En el ámbito inglés, en la era Moderna, a partir del Statute of Forgery de $1563^{40}$, se reproducen multitud de Statutes referidos a la falsificación documental testinada a castigar y disuadir a falsificadores individuales. Es sabido que partir del último cuarto del s. XIV se extiende el ámbito de actuación del documento privado en el tráfico jurídico. Tras el fracaso de la Revolución Campesina (Pesants’ Revolt) de 1381, se intensificó la inmigración de

31 "Exhibens falsum instrumentum praesumitur ipsum falso fabricasse, nisi doceat quis fabricaverit, vel quod ab alio receperit” (CANCER (1683), no. 63, p. 326). También PeñA (1935) vol. XVIII, no 70, p. 185: "El que usare de instrumento falso presúmase que lo hizo hacer".

32 Mieres (1621) vol. I, Collation VI (Petrus III. in Curia Perpiniani), no 26, p. 378: “...quod vtens falso instrumento, si ipse illud falsum non fecit, euitat poenan falsi, si abstineat ab usu illius instrumenti falsi (...). Non tamen eo ipso, quod instrumentum falsum reperitur penes aliquem, debet teneri de falso; nan non est haereticus ille, penes quem libri haeresi inueniuntur, dumodo nolit defendere errores". Véase AlEJANDRE (1972) pp. 157-159.

33 Part., 7, 31, 3: "Todos los yerros (...) que los hombres hacen a sabiendas, con mala intención, son de cuatro maneras (...). La tercera es por escritura, así como cartas falsas o malas cantigas o malos dictados o en las otras escrituras semejantes (...), de que les nace deshonra o daño". Para una relación de "Qué cosa es falsedad y cuando se comete y su pena”, véase PeÑa (1935) vol. XVIII, no 70, pp. 184-187 y Vela Y ACUÑa (1603) cap. X, $\mathrm{n}^{\circ} 3$ : (no es punible) “...si falsis litteris, quis etiam ignoranter utatur...”.

34 Fontanella (1668) vol. I, dec. 290, no 8

35 Castillo (1686) p. 146 (entrada del Index: Instrumentum): "Instrumentum subtraxisse praesumitur is qui ex subtractione commodum percibit".

36 Mieres (1621) vol. I, p. 378, no 26: “...quod vtens falso instrumento, si ipse illud falsum non fecit, euitat poenam falsi, si abstineat ab usu illius instrumenti falsi” y CANCER (1683) vol. I, cap. XX, no 63, p. 303: “...quod exhibens falsum instrumentum eo ipso illud fabricasse praesumittur, quod non docet quis frabricaverit, vel quod ab alio receperit".

37 PeÑA (1935) vol. XVIII, no 70, p. 185.

38 Mieres (1621) vol. I, p. 376, no 12: "Quod vtens falso instrumento punitur leuiori poena, quam falsarius (...) \& potest desistendo euitare poenam".

39 Vela y Acuña (1603) cap. X, no 2, p. 44: "quod vel ex eo apparet, quod licet vt committatur falsum semper dolus exigatur". Más detalladamente, Mieres (1621) vol. I, no 25, p. 378: “...quod adhoc vt falsitas puniatur, requiritur dolus talis, quod aliquem laedat \& profit utenti, quia falsitas non committitur dolo, nisi alius laedatur". Respecto al uso de documento falso y al grado responsabilidad del usuario, véase ALEJANDRE 1972, pp. 157-159.

$40 \quad$ Statute 5 Eliz. c. 14. 
los antiguos vasallos del ámbito rural a los burgos y ciudades emergentes estableciéndose nuevas relaciones de carácter personal, gremial y comercial selladas en documentos priva$\operatorname{dos}^{41}$.

Además, surgen nuevos movimientos político-religiosos, como los Lolardos, seguidores de la doctrina de Wycliff, que intensifican la labor de alfabetización con el objeto de que los más humildes pudiesen tener acceso a los textos sagrados. Aparecen así nuevos amanuenses laicos con capacidad para documentar relaciones jurídicas, pero también para desnaturalizarlas ${ }^{42}$.

\section{EL DOCUMENTO COMO PRUEBA JUDICIAL}

En las Partidas, el documento firmado por notario público u órgano investido de autoridad pública acreditaba el contenido del mismo en causa judicial, aunque los jueces, ante la sospecha de falsificación de instrumento gráfico, podían valerse de expertos calígrafos y, en virtud de su testimonio, el juez podía, a su albedrío, desecharla o darla por válida ${ }^{43}$. Respecto al documento privado, en el texto Alfonsino referido, dispone que el juzgador podía dar validez a la carta privada, estableciéndose en este caso un procedimiento de "probanza" y diversas presunciones para validar o "desechar" el documento ${ }^{44}$.

En los territorios ingleses del Bajomedievo, el documento privado debió tener escasa presencia en juicio como prueba determinante de un derecho o privilegio, probablemente porque no existía consenso para acotar el perímetro de aquellos elementos externos que acreditaban su genuidad. Por ejemplo, para Bracton la autenticidad se acreditaba con la firma de las partes contractuales y de los testigos ${ }^{45}$, mientras que en el Britton y en el Fletd ${ }^{46}$ la genuidad del contenido de un documento se presumía solo con el sello o firma de ambas partes $^{47}$. Es posible que el juzgador evaluase el documento privado con cierto carácter de presunción de veracidad del hombre libre, frente al de menor rango social.

No obstante, ante la proliferación de escrituras privadas falsas, ya a principios del s. $\mathrm{XV}$, tanto el poder real como el eclesiástico reconocen la fragilidad de las relaciones jurídicas en el ámbito civil documentadas en escrituras privadas, de modo que el Parlamento inglés acabó aprobando el Statute Against Forgers of false Deeds en $1413^{48}$ con el fin de dar mayor protección a lo documentado en el ámbito personal y mercantil. En la exposición de motivos el legislador menciona que muchas personas han sido desposeídas de sus propiedades por medio de escrituras falsas y anima a los poseedores de tierras y otras tenencias, cuyos títulos se hubiesen extinguido, extraviado, deteriorado o falsificado, a que acudan a los tribunales para recuperar su título e incluso para ser resarcidos por daños y perjuicios.

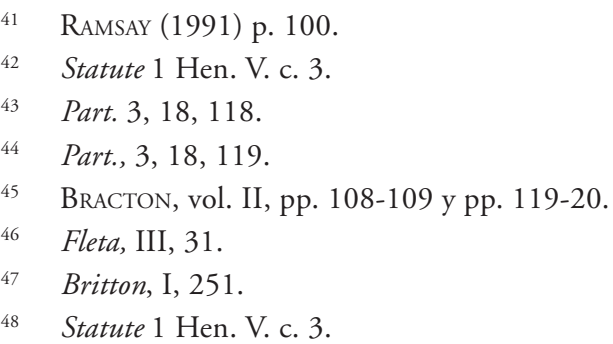


El documento privado fue siempre objeto de controversia por las facilidades de su falsificación, especialmente a finales del s. XV cuando se extendió el uso de la bastardilla itálica y aparecen guías de adiestramiento en el arte de la escritura ${ }^{49}$. La difusión del arte de escribir facilita la maestría en la falsificación en la misma progresión, de modo que la "probanza" de escrituras, especialmente, las de carácter privado, crea gran preocupación en el ámbito de las relaciones mercantiles privadas. Obviamente, el peritaje caligráfico y la prueba testifical son los dos medios más recurrentes para averiguar la autenticidad del documento. Fontanella, en el primer tercio del s. XVII y en referencia a la genuidad de una prescripción dotal en el derecho catalán, advierte de la debilidad de la prueba pericial caligráfica, aunque si se determina pericialmente que la autenticidad de una escritura privada es indubitada, esta ha de servir de referencia en el cotejo con otras del mismo amanuense. Pese a ello, el testimonio pericial se reputa endeble cuando no existen otros medios de prueba. Mayor fiabilidad ha de dársele a la prueba testifical de aquellos que han visto la confección de la escritura en litigio ${ }^{50}$.

En el ámbito inglés la escritura privada no sellada (unsealed writings) no es prueba en juicio ni fuente de reclamación, pues ink and parchment without delivery and acceptance do not make a presentation o a charter is worth nothing without seisin ${ }^{51}$. No obstante, ante la proliferación de documentos privados, especialmente testamentos para los que se requería una forma escrita a partir del Statute of Wills de Enrique VIII, la prueba documental empieza a tenerse en cuenta en el ámbito judicial, aunque se requiera la concurrencia de los testigos que participaron con su firma o presencialmente en la confección del documento al menos hasta la primera mitad del s. XVI, prevaleciendo siempre la prueba testifical sobre la documental ${ }^{52}$.

No obstante, la mayor preocupación regia era la falsificación de documento público. En el ámbito hispánico, el monarca del Bajomedievo ya se vio ante la necesidad de dictar instrucciones reales para delimitar con claridad quién estaba autorizado a "dar cartas en casa del rey" 53 , alertando, además, a los administradores de justicia de las diferentes formas

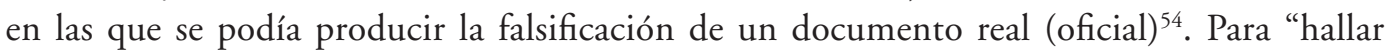
medios que sirvan de remedio a tanto exceso", Felipe IV, en su pragmática de 15 de diciembre de 1636, lamenta que ni sus reales leyes, ni las penas prescritas, ni sus Justicias tienen suficiente capacidad para la erradicación de instrumentos y escrituras públicas falsas. Para ello, dispone que se extienda el uso de papel sellado en las escrituras, autos e instrumentos públicos, irrogándose de facto la presunción iuris tantum de que el instrumento confeccionado en papel sellado tiene pleno efecto jurídico y es prueba incontrovertida en juicio ${ }^{55}$.

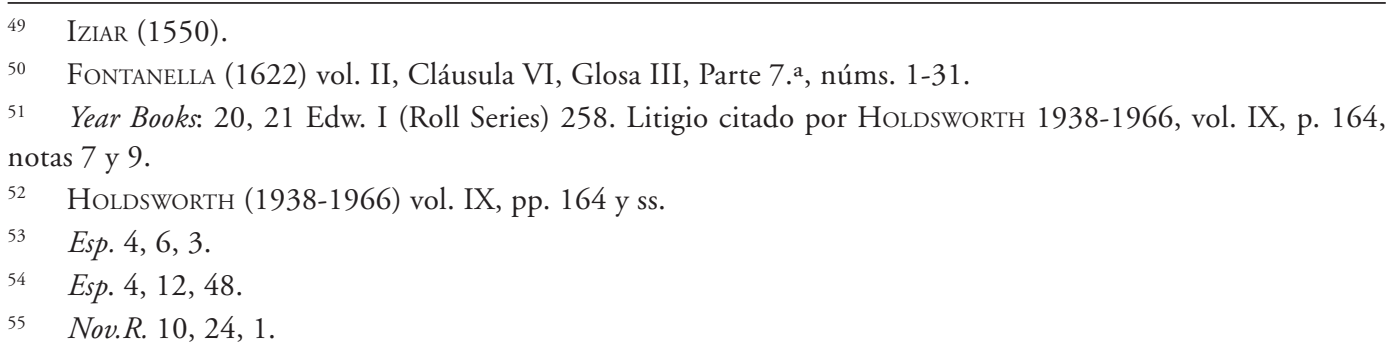


La prueba documental cobra importancia en la Modernidad tardía y se impone a la prueba testifical allí donde el documento no presente signos de desnaturalización. En el ámbito hispánico se dispone que el actor "puede probar su demanda por escrituras", y el demandado tiene la oportunidad de oponerse aportando otras o de impugnar aquellas y "si cualquiera de las partes diere y jurare, que las quiere redargüir de falsas, que en tal caso le sean mostrados los originales a cualquiera de las partes que las quisiere ver y a su Procurador y Letrados; y le sea dada copia y traslado con día, mes y año, para que alegue de su derecho" 56 .

En el ámbito inglés la prueba documental empieza a ser determinante a partir del s. XVII. Por una parte, en este siglo se desarrolla la jurisdicción mercantil como consecuencia de la multitud de operaciones de carácter económico que empiezan a extenderse en las grandes ciudades junto a las relaciones comerciales con los países de ultramar. La mayoría de las controversias jurídicas en este campo se amparan en instrumentos documentales (pagarés, promesas de pago, certificados de depósito, etc.). Por otra parte, el antiguo sistema de perfeccionamiento contractual consistente en delivery and acceptance en la transmisión de derechos reales, sin necesidad de un documento acreditativo, cambia tras el Statute of Frauds ${ }^{57}$ de 1677, pues en dicha norma se exige que la transmisión de pleno dominio (livery of seisin) se acompañe de escritura. Este Statute viene a dar prioridad a la prueba documental sobre la testifical, advirtiéndose, además, que el documento firmado no podrá tampoco ser modificado por testimonio de testigos ${ }^{58}$.

\section{CALIFICACIÓN DEL DELITO EN EL ÁMBITO HISPÁNICO EN LA ERA MODERNA}

La caracterización del delito de falsedad documental en los diversos cuerpos jurídicos territoriales de la Modernidad hispánica hasta el período de la codificación se configura en torno a una enumeración abierta de conductas falsarias que pueden adoptar múltiples formas. La regulación legislativa del instituto del crimen falsi acogida en la Nueva y Novísima Recopilación es una reproducción de las Partidas. De modo que la extensa variedad de "realidades" documentadas, junto con la amplia gama de matices de la noción de "falso" jurídico perpetuaron la indeterminación del ámbito material del delito en la era Moderna. Por otra parte, tampoco se había acotado por el legislador el grado de intervención textual mínima para que irrogase el delito. Será la doctrina jurídica la que configure la acción delictiva en función de la capacidad del documento para producir efectos en el tráfico jurídico. Si bien algún jurista sostiene que toda alteración del instrumento gráfico, aunque no afectase a la esencia del mismo, debía ser punible. Así lo entienden López de Salcedo o Mieres ${ }^{59}$. La calificación penal del delito estaba, pues, en función de las circunstancias de su

Nov. R., 11, 3, 1 y 2 .

29 Cha. 2, cap. 3.

Con mayor detalle, Holdsworth (1938-1966), en concreto, el epígrafe "The rules governing the effect of documentary evidence", pp. 175-177.

59 LÓPEZ DE SALCEDO (1566) cap. CXX, no 5, p. 409: "Erit etiam à dicta poena ordinaria immunis, qui dictar. literarum Apostolicarum mutat punctum, vel corrigit literarum aliquim, quando non mutatur substantia” o MiERES 
comisión y del grado de responsabilidad del transgresor, por eso será el juez, a su arbitrio, el que determine el castigo aplicable dentro del elenco de penas disponibles (multa, destierro, vergüenza pública o confinamiento)..

\subsection{TRATAMIENTO PROCESAL DEL DELITO. LA REAL AUDIENCIA Y CHANCILLERía DE VALLADOLID \\ Una primera revisión de los casos de falsedad documental en las Ejecutorias de la} Real Audiencia y Chancillería de Valladolid en la Modernidad temprana muestra que en la mayoría de los casos la acusación de falsificación documental se encuadra en el marco de otra causa en litigio. Así, es habitual que se recurra el disfrute de un derecho que otro posee por haberse servido de un documento acreditativo reputado falso. En estos supuestos, lo que realmente se debate es quién es el titular del interés jurídico, aunque también entra en el litigio el medio probatorio que acredita ese derecho. Sirva de ejemplo la Ejecutoria de 23 de diciembre de 1590 en la que se alude al pleito entre Catalina Coceña, vecina de Luces de Lastres (Asturias) y Toribio Alonso de Cobián, escribano, vecino de Colunga (Asturias). Según la actora, el escribano confeccionó un testamento falso para adueñarse de los bienes que le habrían correspondido a ella ${ }^{60}$. En este litigio la actora no busca realmente un pronunciamiento aislado sobre la supuesta falsedad del documento, sino que su pretensión se dirige a obtener una resolución judicial que le dé derecho a la posesión y propiedad de los bienes en litigio.

Repárese, además, que el documento que se reputa falso no tiene por qué ser determinante en la resolución del pleito, dado que el juez puede valerse de otros medios probatorios. No obstante, cuando el medio de prueba decisorio es el documento que se presume espurio, probada su falsedad, el juez dictará resolución sobre el derecho debatido. A veces el mismo juzgador dicta sentencia y su ejecución respecto de la causa principal, y prosigue con el encausamiento del infractor de falsedad documental ${ }^{61}$.

La tipología de documentos falsos es muy variada destacándose la falsificación de escrituras que recogen algún tipo de negocio jurídico de carácter privado con aptitud para transitar en el tráfico jurídico o como instrumento probatorio en sede judicial. De las 242 Ejecutorias observadas de la Real Audiencia y Chancillería de Valladolid y pleitos de la Sala de Vizcaya entre 1500 a 1650 en los que se plantea un supuesto de falsedad documental, bien como causa principal o como accesoria a otra causa en litigio, en 189 causas se registra falsedad de documento o escritura que afecta a la esfera privada. En particular, la falsificación del contenido de un documento de carácter patrimonial en el que se recoge supuestamente una artificiosa acreditación de: (i) venta y transmisiones de predios, casas

(1621) vol. I, Collation VI (Petrus III. in Curia Perpiniani), no 17, p. 377: "quod hodie est praeceptum, quod in litteris Papae, nec in magno, nec in modico audeat quis manum apponere, etiam litteram vnicam, vel punctum vnicum corrigendo...". Véase AlEJANDRE (1972) p. 157.

60 Real Audiencia y Chancillería de Valladolid, ARCHV, Ejecutorias (en adelante, Ej.), Caja (en adelante, C.) $1684,51$.

$61 \quad$ Ej., C. 30, 1. 
y animales ${ }^{62}$; (ii) donaciones ${ }^{63}$ y (iii) dotes ${ }^{64}$, (iv) cartas de pago o documentos de deuda ${ }^{65}$, y (v) alteración o modificación de libros de contabilidad ${ }^{66}$. Es igualmente recurrente la falsificación de elementos externos acreditativos del documento, entre los que se incluye: (i) suplantación de la personalidad con incorporación o alteración de firmas falsas ${ }^{67}$ y (ii) confección y uso de poderes de representación ${ }^{68}$. En el ámbito de la potencial falsedad tiene especial incidencia la confección de testamento falso ex novo ${ }^{69}$, desnaturalización de testamento genuino ${ }^{70}$ e inclusión de nuevas disposiciones testamentarias ${ }^{71}$.

En las Ejecutorias observadas, los supuestos de falsedad en documento público son menos frecuentes, en tanto que se documentan 53 casos, de los 242 que se han manejado; y muchos de ellos relativos a la falsificación de documentos del propio proceso judicial. Así, se registran 13 casos de falsedad en documentos concernientes a las pruebas judiciales ${ }^{72}$. Al menos en 7 litigios se aduce falsedad en la reproducción del testimonio de testigos ${ }^{73}$. Igual número de casos se registran con incriminación de falsificación de diligencias o instrumentos procesales ${ }^{74}$ y en menor medida mandamientos judiciales ${ }^{75}$, sentencias ${ }^{76}$, provisiones de emplazamiento $^{77}$, provisiones reales de diligencias ${ }^{78}$ o cédulas $^{79}$. Recurrente es también la falsedad de títulos profesionales, especialmente el de escribano, abogado, médico y artesano (por ejemplo, cordonero ${ }^{80}$ ) o de credenciales de nombramiento de cargo público ${ }^{81}$, de títulos de concesión o disfrute de privilegios y fueros ${ }^{82}$. Se documentan también supuestos de suplantación de la personalidad, de padrón o de instrumentos de filiación ${ }^{83}$. A lo que

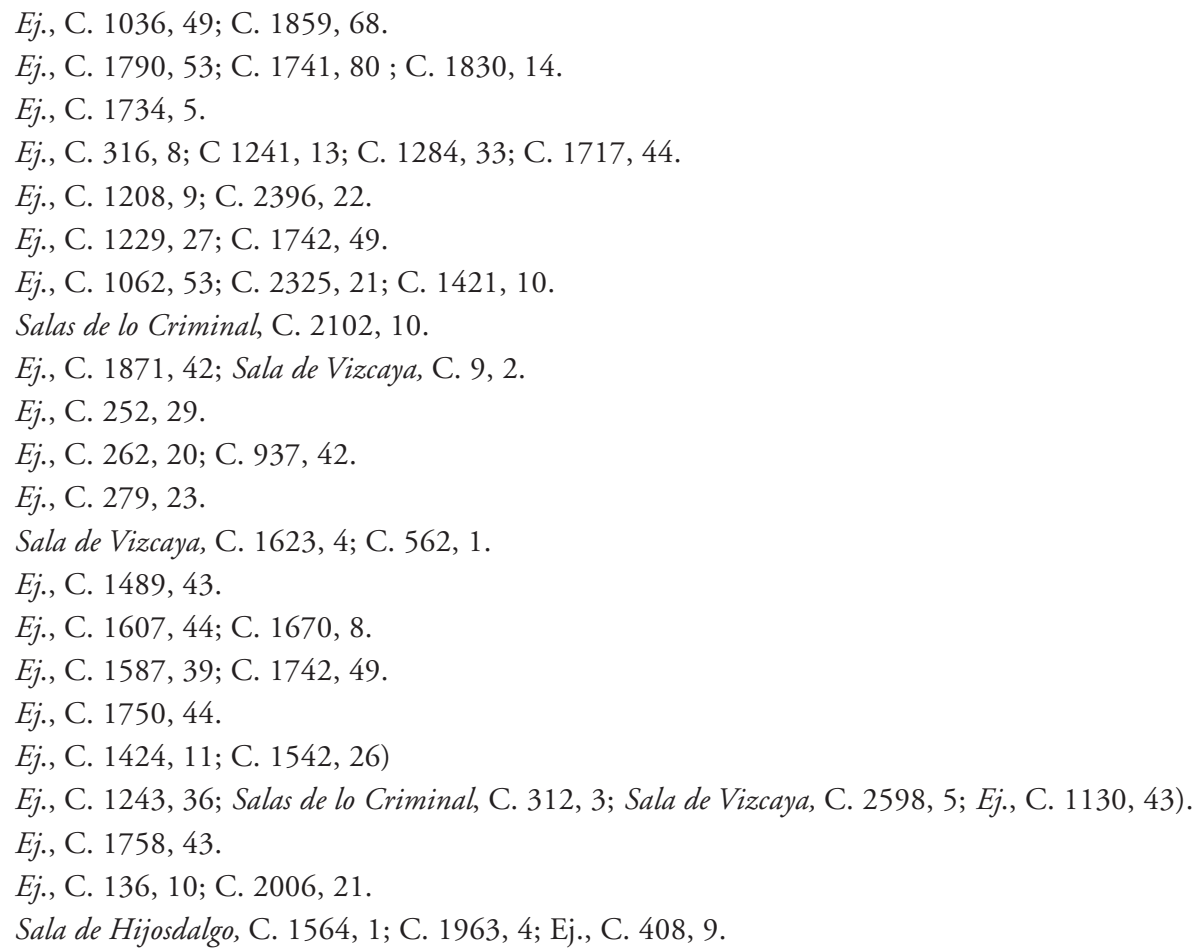


habría que añadir aquellos casos de falsificación de signos externos del documento, siendo el más reiterativo la falsificación del sello ${ }^{84}$ o de las firmas ${ }^{85}$.

Pese a la variada tipología de documentos que son objeto del delito, el perfil del documentante falsario es mucho más restrictivo, en tanto que al menos en la mitad de los casos observados (115 de 226) se acusa a un escribano ${ }^{86}$. En la mayoría de los litigios la acusación contra el escribano se entabla a instancia de parte ${ }^{87}$, aunque al menos en 11 causas es el fiscal del rey quien incoa un proceso separado contra el escribano bajo la acusación de mal uso de su cargo o abuso de poder en el ejercicio de su oficio ${ }^{88}$.

Así pues, en toda la Edad Moderna (temprana y tardía), la mayor parte de los pleitos por falsificación documental en la Real Audiencia y Chancillería de Valladolid se plantean a instancia de parte bajo la acusación de falsedad cometida por escribanos. Estos conforman un colectivo numeroso y heterogéneo con diferentes rangos y escalas: escribanos del rey, escribanos del número, escribanos concejo o municipio, escribanos encargados de archivos, escribanos contables y administradores de instituciones nobles, etc. Piénsese que en esta ápoca se redactan o actualizan una cantidad ingente de escrituras privadas que acogen un negocio jurídico entre partes en el que al menos una de estas desconoce la escritura. Además, muchos de los escribanos carecían del adiestramiento necesario para ejercer su oficio. Muchos de ellos habrían adquirido el título por cesión real ("venta") a perpetuidad ("por juro de heredad"89).

Además, el escribano instruía, a su costa, gran parte de las diligencias judiciales de un caso, de modo que activaban los diligencias a veces de forma fraudulenta para cobrar su estipendio; y para ello es probable que algunos no dudasen en falsificar testimonio de testigos, diligencias, etc. Sirva de ejemplo, el pleito en el que Martín de Burgoa, escribano de Bilbao (Vizcaya) es acusado por Pedro de Poza en 1563 por falsedad de aquel en la redacción de las escrituras e instrumentos judiciales ${ }^{90}$.

\subsection{RÉGIMEN SANCIONADOR}

En la Modernidad temprana, el régimen sancionador sigue siendo básicamente el de las Partidas ${ }^{11}$, de modo que el que falsificase bula, firma o sello del Papa o del monarca incurría en pena de muerte, mientras que el que cometiese falsificación de escrituras privadas en perjuicio ajeno era condenado a la pena de destierro y confiscación de bienes, junto con la pérdida del litigio en causa civil. Existe todavía cierta imprecisión respecto a si la aportación en juicio de un documento falso irrogaba solo la pérdida de la causa o si además el falsario era castigado con la pena ordinaria o arbitraria. Es posible que una de las partes presentase documento falso junto a otras pruebas idóneas, de suerte que el instrumento

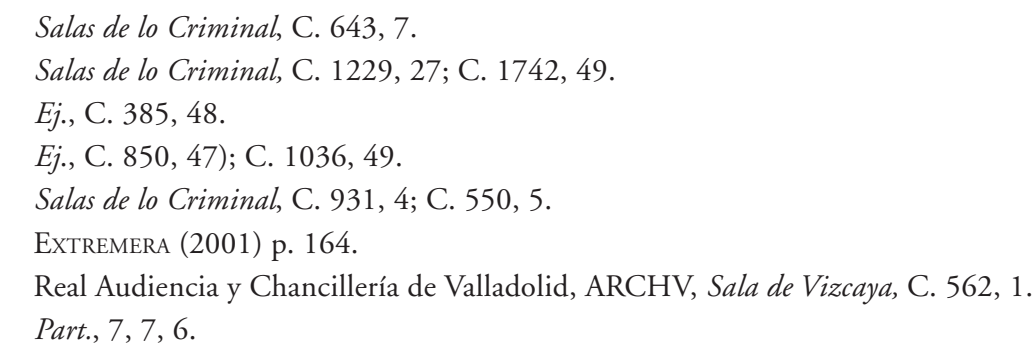


espurio no fuese determinante para dictar la resolución. Siendo así, cabría pensar que o bien el documento falso se habría ignorado y también la acusación de falsedad o, por el contrario, la simple comprobación de la falsedad del instrumento espurio, aun no siendo determinante para la resolución, irrogase la pérdida de la causa y la imposición de castigo para el falsario. Según la opinión doctrinal, al menos en el derecho catalán, la aportación de documento falso como prueba judicial comportaba la inmediata pérdida de la causa sin ulteriores efectos ${ }^{92}$.

Para el falsario cualificado, escribano o notario, se prescribía pena de amputación de mano también en la Modernidad temprana. No obstante, según nos recuerda Antonio de la Peña, la pena de mutilación, pese a que seguía vigente en el último cuarto del siglo XVI en el ordenamiento real castellano, ya no se aplicaba, salvo como método punitivo de agravamiento de la ejecución de la pena capital para delitos atrocísimos o de "pecado nefando" ${ }^{93}$. Los castigos impuestos al fedatario público fueron suavizándose hasta tal punto que, según Berni, en su época (s. XVIII) solo se le castiga con pérdida de oficio con carácter temporal y alguna multa ${ }^{94}$. La práctica procesal de la segunda mitad del s. XVIII viene a corroborar que se aplica generalmente pena pecuniaria arbitraria ${ }^{95}$ y, según los casos, destierro o mul$\mathrm{ta}^{96}, \mathrm{y}$ también presidio en África "en calidad de gastador" para supuestos agravados ${ }^{97}$. Estas penas podían acumularse atendiendo a las circunstancias del delito, las personas o instituciones afectadas y el carácter cualificado del falsario (como era el caso de escribano ${ }^{98}$ ). Aunque como señala Posadilla, en su época la sanción impuesta al escribano no es la ordinaria, sino la arbitraria, que se limita a "suspensión de oficio y alguna multa".

La pena del delito de falsedad documental, como en otros delitos, se va adaptando en el primer cuarto del s. XIX a las necesidades de la Corona para las infraestructuras públicas o para la defensa de los territorios hispánicos. Así en el primer código penal hispánico de 1822 en su art. 388 se sanciona a los que "falsifican los sellos de las Córtes, ó del Rey,

92 CANCER (cito por ed. de 1683): "In Cathalonia producens falsum instrumentum scienter, amittit causam, secus de iure communi" (vol. I, cap. XX, núm. 60, p. 326); "An producens falsam scripturam in eo capite ubi non est vis quaestionis, causam amittat" (Ibid., núm. 68, p. 327) o "An si procurator falsos testes aut instrumenta produxerit, puniatur dominus amissione causa” (Ibid., núm. 69, p. 327). Del mismo modo, Fontanella, también señalaba: "...qui scienter vel testes in causa civili...vel in ea causa instrumenta falsa produxerit scienter, poena amissionis causae plectendum forc" (Fontanella (1668), Tomo I, Dec. 290, núm. 2).

93 PeÑa (1934) vol. XVII, nº 69, pp. 796-797. También, refiriéndose a la pena de vergüenza pública para los delitos de armas, véase Ortego (1998) p. 159.

94 De hecho, Berní i Català se lamenta del escaso rigor con que se castiga al escribano falsario: "pero eso de arbitrar el juez como en las penas que las mismas leyes dejan a su arbitrio, imponiéndole solo una corta suspensión de oficio y alguna multa, en la falsedad sustancial, juzgo que es exceso en el juez, y que quebranta la ley, pues ni la letra ni su espiritu observa, usando de arbitrios en las penas de falso escribano que las leyes han señalado" (Berní I CATAlà (1749) cap. XXIII, núm. 2, pp. 53-54.

95 Real Audiencia y Chancillería de Valladolid, ARCHV, Ej., C. 2325, 21 (diciembre de 1621).

96 Mattheu y Sanz (1686) Controv. XXXVIII, no 32, p. 299: "Et sic poena tabellionis acta falsificantis de jure Hispano est amputationis manus, et infamia juxta (...). Sed quia inhumana poena hujusmodi amputationis visa fuit...”. Para una mayor concreción en el régimen sancionador del escribano público en los diferentes territorios hispánicos, véase ALEJANDRE (1972) pp. 170 y ss.

${ }_{97} \quad$ Sirva de ejemplo el caso dirimido en la Chancillería de Granada en 1777 (Razón del juicio seguido en la ciudad de Granada (1781) pp. 364-368.

98 Álvarez Posadilla (1833) pp. 442-443. 
ó de las autoridades y oficinas del Gobierno, ó las actas ó resoluciones de las Cortes, las cédulas, títulos, despachos y decretos reales" con pena de trabajos perpetuos. Mientras que en el art. 398 "las falsedades, supresiones y omisiones que se cometan en escrituras ó actas judiciales ú otros documentos públicos ó de comercio” son punidas con la pena de infamia, de diez a veinte años de obras públicas e inhabilitación perpetua. En cambio, "las falsedades en documentos privados, sellos, marcas y contraseñas de los particulares" se castigan con la pena de infamia y pena de dos a seis años de reclusión.

\section{LA CALIFICACIÓN DEL DELITO EN EL ÁMBITO INGLÉS EN LA ERA MODERNA}

El Statute de 1413 sigue calificando de delito menos grave (misdemeanour) la falsificación de documentos privados que, a sabiendas y con perjuicio de terceros, se realiza en beneficio propio, estableciéndose en causa civil pena pecuniaria y resarcimiento de daños a la víctima, mientras que el infractor cualificado recibiría la pena corporal de mutilación de la mano transgresora como sistema expeditivo de inhabilitación perpetua, castigo que llevaba incorporado la pena accesoria de infamia. Como se puede apreciar, el reproche penal es similar al contemplado en los territorios hispánicos de la época.

Lo relevante, a diferencia de los ordenamientos hispánicos, es que el Statute Against Forgers of false Deeds de 1413 proporciona a la parte perjudicada -por uso de documento falso de contrario- no solo la correspondiente acción reivindicatoria de propiedad o dominio, sino también una acción civil por daños y perjuicios contra aquellos que forged and proclaimed any false deeds y para los que entorpecían el disfrute del título o la posesión con documentos falsos ${ }^{99}$.

Esta nueva legislación permitió a los tribunales del Common Law disponer de nuevos títulos de punición para sancionar al falsificador de documento privado. La práctica forense así lo demuestra. Así, los datos que arrojan los Year Books, en relación a las causas que se sustanciaron en el Common Pleas Court de Westminster entre 1268 a 1525 revelan que este tribunal empezó realmente a enjuiciar y sancionar el delito de falsedad de documento privado a partir de la década de 1420. Así, los Year Books no recogen ningún pleito por falsedad de documento privado antes de la promulgación del Statute Against Forgers of false Deeds de 1413, mientras que entre 1420 y 1460 se diriman 39 causas en juicio separado reclamando daños y perjuicios de un total de 45 que se observan en todos los registros de los Year Books entre 1268 a 1525.

En todo caso, de las 22.318 causas registradas en los Year Books dirimidas en el Common Pleas Court de Westminster entre 1268 a 1525, solo 45 se encausan directamente o se alude a aportación de prueba documental falsa. Cabe también reseñar que solo hemos localizado en los Year Books un caso de enjuiciamiento y condena de un reo convicto de falsificación de documento público regio -Forgery of the king's commission and misusing the king's seal-, en 1401, lo que prueba también la escasa incidencia de este delito de traición en la práctica forense inglesa en este período bajomedieval tardío.

99 Statute, 1 Hen. V, c. 3. 
Después de un largo siglo de escasa efectividad a efectos procesales del Statute of Forgery de 1413, se promulga en 1563 un nuevo Statute of Forgery ${ }^{100}$. Se motiva su promulgación por la creciente importancia de los documentos escritos de naturaleza privada, siendo especialmente vulnerables los instrumentos comerciales y financieros que operaban en el tráfico jurídico mercantil.

El Statue de 1563 delimita de algún modo el ámbito material del delito, pues viene a sancionar: (i) la alteración de alguno de los elementos esenciales del contenido del documento; (ii) la alteración o simulación de algún signo externo del documento que afectase a su autenticidad; y (iii) la alteración de la identidad de las personas que interviniesen en el documento o la atribución -a las que habían intervenido en él- de declaraciones o manifestaciones diferentes de las que hubieran hecho, o simplemente faltar a la verdad en la narración de los hechos.

La mayor inconsistencia de esta ley isabelina fue sin duda la falta de concreción en la calificación del delito, pues solo la primera reincidencia elevaba su calificación a crimen de felonía, pero se necesitaba una segunda reincidencia para que el delito se considerase realmente non-clergiable y, consecuentemente, penalizado con pena capital. Bien es cierto que, a la luz de nuestro tiempo, el castigo del infractor primerizo nos puede parecer realmente cruel, pues al convicto se le sancionaba con penas acumulativas que incluía: (i) confiscación patrimonial equivalente al doble del daño causado; (ii) pena de picota en lugar púbico con enclavamiento de sus dos apéndices auriculares al poste y posterior mutilación; (iii) perforación de sus fosas nasales con hierro candente -lo que acarreaba la nota de infamia perenne-; (iv) confiscación a favor de la corona el producto de sus tierras; (v) reclusión a perpetuidad en prisión, y (vi) la liquidación de los costes judiciales. No obstante, la ley de 1563 preveía menor sanción atendiendo a si la falsificación no afectaba a la parte sustancial del documento - no se alteraba las referencias a fechas, ni las obligaciones o rentas contraídas, ni a la cancelación de cargas, gravámenes, etc.-. En este caso, el convicto se seguía sancionando con confiscación del duplo del daño causado, la exposición en la picota, pero solo la mutilación de una de sus orejas y medio año de prisión. Si reincidía su delito se calificaba de felonía sin "beneficio del clero", lo que le acarreaba la pena de muerte por ahorcamiento y la confiscación a favor de la corona de todos sus bienes.

Pese al rigor de la Ley isabelina de 1563, un siglo más tarde surgen voces para endurecer el castigo de los falsificadores de documentos privados elevando su calificación a felonía. A finales del s. XVII empiezan a proliferar documentos mercantiles y bancarios (cheques, letras de cambio, pagarés, etc.) que están siendo objeto de falsificaciones por profesionales del crimen. Los miembros del Parlamento, en su mayoría personas de respetabale patrimonio y con intereses en el nuevo mercado financiero y comercial, son los primeros perjudicados por la falsificación de documentos mercantiles e instrumentos financieros en papel, por eso no dudan en legislar a favor de sus propios intereses.

En la segunda mitad del s. XVII el soporte papel se afianza como instrumento del sistema monetario, se intensifica la economía privada y las relaciones comerciales a gran escala entre particulares o entre instituciones bancarias y particulares, y todo ello se regulariza

100 Statute 5 Eliz. c. 14. 
en documentos públicos y privados. Por tanto, la proliferación de este tipo de documentos originó un incremento del delito de falsificación de los mismos ${ }^{101}$. Para erradicar estas conductas el legislador ya había previsto el endurecimiento del delito de falsedad documental desde 1697 para ciertos casos de falsificación de instrumentos financieros y bancarios ${ }^{102}$.

No obstante, es el Statute de 1729 el que produce un cambio radical en la sanción al prescribirse la pena capital para el falsificador de documento privado destinado al tráfico jurídico $^{103}$. Probablemente, el suceso ocurrido en la ciudad de Londres en 1728 cuando un conocido orfebre, William Hales, había falsificado multitud de instrumentos bancarios defraudando a conocidos personajes de la sociedad londinense, entre ellos, a muchos parlamentarios, propició la aprobación de este Statute. El Tribunal Penal Central de Londres, fruto de la legislación en vigor, solo pudo condenar a William Hales a la pena de picota, multa y prisión perpetua.

La casuística de la falsificación documental era tan extensa que se fue regulando según se iban perfeccionando los delitos, de modo que solo en el s. XVIII nos encontramos con 36 Statutes que directa o indirectamente están relacionados con el delito de falsedad documental ${ }^{104}$. Así, el Statute de 1729 de Jorge II se ve modificado 5 años más tarde por un nuevo Statue que amplía la casuística de instrumentos bancarios potencialmente objeto de falsificación ${ }^{105}$. En el reinado de Jorge III se extiende el ámbito material y subjetivo del delito penalizando también la posesión del papel o instrumentos mecánicos utilizados en la falsificación de documentos de cualquier naturaleza destinados al tráfico jurídico ${ }^{106}$.

Aunque queda fuera del objeto de este estudio la falsificación de moneda, considerada una ofensa contra la Corona, interesa hacer mención a la emisión de los billetes de una y dos libras por el Banco de Inglaterra en 1797, pues la circulación de estos billetes propició una masiva falsificación de los mismos y al menos uno de cada tres reos condenados a muerte y ejecutados por el TPCL entre 1805-1818 es por este delito al que Dickens no dejó de criticar ${ }^{107}$. Nótese, pues, que este tipo de falsificación de billetes no se encuadraba en los delitos contra la Corona (falsificación de moneda), sino como delitos de falsedad documental (forgery).

7.1. EnCAusamiento y régimen SAnCionador. El tribunal penal Central de LONDRES

La práctica forense del Tribunal Penal Central de Londres (en adelante, TPCL) se adapta a la nueva legislación penal que va surgiendo con diferentes textos normativos. Para ver la evolución del régimen sancionador del delito de falsedad documental en el TPCL interesa distinguir dos etapas: i) 1674-1729; y ii) 1730-1830.

\footnotetext{
101 Sharpe (1999) p. 253.

102 Statute 7 y 8 Wil. 3. c. 31; ya en el s. XVIII, Statute 11 Geo. I, c. 9 y Statute 12 Geo.I, c. 32.

103 Statute, 2 Geo.2 c. 25. También BLACKSTONE (1765-1979) 1a ed. vol. IV, pp. 246-247.

104 Holdsworth (1938-1966) vol. XI, p. 534 y STEPHen (2014) 1 a ed. 1883, vol.. III, pp. 180-188.

105 Statute 7 Geo. 2. c. 22.

106 Statutes 13 Geo. 3. c. 79; 15 Geo. 2. c. 13; 18 Geo. 3. c. 18 y 41 Geo. 3. c. 49.

107 "the days of the uttering of forged one-pound notes' when 'hundreds of wretched creatures of both sexes -many quite innocent-swung out of a pitiless and inconsistent world' [DiCKENs (1997) p. 75].
} 
(i) El primer período que discurre de 1674 (fecha del primer registro del TPCL) a 1729, cuando se establece un nuevo régimen penal para el delito de falsificación documental con el Statute of Forgery de Jorge II. En esta etapa el TPCL impuso la pena de muerte a convictos de falsificación del sello real o de autoridad pública como ya se venía haciendo desde la época altomedieval por considerarse un delito de traición ${ }^{108}$, pero también dicta pena capital por falsificación de letras del tesoro ${ }^{109}$, de billetes bancarios ${ }^{110}$ y de endosos de pagarés de gran cuantía ${ }^{111}$ bajo la acusación de felonía, caracterización que se prescribe en la ley penal de Guillermo III en la última década del s. XVII para la falsificación de efectos bancarios o financieros ${ }^{112}$. La falsificación de documentos públicos de carácter administrativo y judicial, que mantienen la calificación de misdemeanour, se castigan con pena de picota, multa y prisión por el TPCL ${ }^{113}$, aunque la reincidencia en la falsificación de estos documentos públicos se tipifica como felonía y se sanciona con la pena capital ${ }^{114}$.

No obstante, la adulteración de documentos privados sigue todavía en la categoría penal de misdemeanour, y consecuentemente el TPCL dicta, sin excepción, la pena principal de picota ${ }^{115}$ y las accesorias de prisión temporal, generalmente entre 6 meses a 1 año, y multa en atención a la concurrencia de alguna circunstancia agravante en la comisión del delito $^{116}$. En suma, el TPCL dirime en este primer período (1674-1729) 126 causas por falsedad documental, en 101 el jurado declara culpabilidad, aunque solo en 81 con reo diferente, por tanto dicta 81 condenas; de ellas, 10 de pena de muerte (traición y felonía) y 71 de pena principal de picota y penas accesorias de multa y prisión.

(ii) En el segundo período (1730-1830) el TPCL aplica un régimen sancionador mucho más riguroso tras la promulgación del Statute of Forgery georgiano en $1729^{117}$ y que se mantiene vigente hasta el Forgery Act de $1830^{118}$. Este período que abarca un siglo viene a coincidir con la época del Bloody Code en el que se endurecen las penas de la mayoría de los delitos, especialmente los que atentan contra la propiedad. En este período (17301830), el TPCL dicta la pena capital a convictos de falsificación de documento regio, pú-

108 OBP, July 1697, trial of Samuel James (t16970707-10); OBP, October 1724, trial of Abraham Deval (t17241014-42); OBP December 1729, trial of Peter Coffey (t17291203-56) o OBP, January 1731, trial of William Maynee (t17310115-77), por citar algunos.

109 OBP, October 1699, trial of John Bellingham (t16991011-31).

110 OBP, January 1722, trial of George Nicholas (t17220112-11).

111 OBP, December 1729, trial of Peter Coffey (t17291203-56).

112 Statute 7 y 8 Wil. 3. c. 31. Véase OBP, October 1699, trial of John Bellingham (t16991011-31] o OBP, January 1722, trial of George Nicholas (t17220112-11), por citar algunos.

113 John Ingham, acusado de elaborar una orden judicial falsa, es castigado con picota y multa [OBP, May 1689, trial of John Ingham (t16890516-75)] o William Saunders and John Bartholomew Earl [OBP, March 1721, trial of William Saunders John Bartholomew Earl (t17210301-62)].

$114 O B P$, October 1724, trial of Abraham Deval (t17241014-42).

115 Por ejemplo, OBP. January 1712, trial of Sarah Harris (t17120111-12)]o OBP, May 1717, trial of Mary Hinchley (t17170501-50).

$116 O B P$, November 1716, trial of Sarah Ambrose (t17161105-92) o OBP, July 1727, trial of Edward Anchors (t17270705-51)], entre otros.

117 Statute, 2 George II, c. 35.

118 Statute, 11 Geo 4 \& 1 Will 4 c 66 
blico $^{119}$, bancario, financiero ${ }^{120}$ y también privado, especialmente vulneración de testamento ${ }^{121}$.

Los registros de los Sesion Papers del TPCL arrojan los siguientes datos para este segundo período (1730-1830): se enjuician 1.038 causas por falsedad documental. Lo sorprendente es que solo se halla culpabilidad del reo en 545 casos, y lo más significativo es que a 375 (el 68.8\% de los culpables) se les condena a pena de muerte. El último condenado a muerte y ahorcado es Thomas Dominick en 1835, acusado de falsedad en testamento ${ }^{122}$.

Sin embargo, cae en desuso la pena de picota para los delitos de falsedad de documento privado calificados de misdemeanour. En realidad, solo hemos localizado dos registros en este período, en $1731^{123}$ y el último en 1744 , cuando a John Hammand, acusado de publicar una carta a sabiendas de que era falsa con la intención de estafar a Nicholas Durant, se le castiga con la pena de picota en el poste de ejecución de Chancery-Lane en la calle Fleet-street, junto con las penas accesorias de multa de 6 s. 8 d., un mes de prisión ${ }^{124}$.

Sorprende también que, pese a que el TPCL impone desde 1754 pena de deportación para castigar la falsedad documental, como alternativa a la pena de muerte en casos menos graves, sin embargo solo se registran 18 condenas de deportación entre 1754 (fecha de la primera sentencia) hasta 1810 . No obstante, entre 1811 y 1830 aumentan considerablemente, dictándose 107 condenas de deportación por este delito.

Para ver el contraste entre el primer y el segundo períodos, sirvan de ejemplo estos tres casos. Mientras que a Henry Waldron, que había falsificado un recibo de deuda de 300 libras, el TPCL le condena en el año 1700 a la pena de picota y multa ${ }^{125}$, a William Newington acusado de reproducir un cheque bancario falso de 120 libras en 1738 es condenado a muerte y ejecutado ${ }^{126}$. Pero ya a finales de siglo, en 1790, el TPCL condenó también a la pena de muerte a Francis Fonton, acusado de falsificar un recibo de deuda de solo 50 $\operatorname{libras}^{127}$.

Sin embargo, como ya se ha mencionado, todo parece indicar que los jurados optaban por el veredicto de inocencia ante el rigor de la ley, aun existiendo indicios inculpatorios $^{128}$. En la primera década (la de 1730) en que los tribunales tendrían que aplicar la pena máxima también por falsificación de documento privado en aplicación del Statute of

119 OBP, January 1731, trial of William Maynee (t17310115-77).

120 OBP, May 1732, trial of Edmund Cheesborough (t17320525-9).

121 OBP, April 1734, trial of William Fletcher (t17340424-20)]. La falsificación de testamento es objeto de pena capital en esta época, sirvan de ejemplo los siguientes: $O B P$, July 1737, trial of Catherine Leng (t17370706-9); OBP, December 1741, trial of Dominick Fitzgerald James Lee (t17411204-21); OBP, April 1742, trial of Robert Rhodes (t17420428-33); OBP, July 1744, trial of James Gulleland (t17440728-31); OBP, December 1750, trial of Catharine Conner (t17501205-76), etc.

122 OBP, August 1835, trial of Thomas Dominick Feeley (t18350817-1694).

$123 O B P$, December 1731, trial of Mordecai Jacob Duvries (t17311208-47).

$124 O B P$, July 1744, trial of John Hammand (t17440728-44).

$125 O B P$, January 1700, trial of Henry Waldron (t17000115-28).

$126 O B P$, June 1738, trial of William Newington (t17380628-26).

$127 O B P$, September 1790, trial of Francis Fonton (t17900915-37).

128 OBP, May 1719, trial of John Mills (t17190514-47). 
Forgery de 1729, en gran parte de los casos, buscaron una fórmula para evitar la severidad de la pena que consistía básicamente en declarar la inocencia del acusado. Eso explica que mientras en la década de 1720 en la que todavía no se prescribía legalmente la pena de muerte para el convicto de falsedad documental, el número de reos considerados culpables por el TPCL es de 22, mientras que los de innocencia son solo 13. Sin embargo, en la década siguiente cuando ya se tiene que aplicar la pena capital por este delito, se revierte la proporción, dado que los veredictos de culpabilidad se reducen a 10 y los de inocencia aumentan a 18. La serie por décadas de veredictos de inocencia, sobrepasando con creses a los de culpabilidad, sigue constante en el período en que la pena de muerte estuvo prescrita por la ley para el castigo de documento privado, esto es, hasta hasta la década de 1830. La imputación de culpabilidad cambia de nuevo drásticamente en la década de 1840, en la que observamos que en esa década recibieron el veredicto de culpabilidad 485 reos frente a los 169 que se declararon veredictos de inocencia y en las siguientes décadas hasta 1900 la desproporción es cada vez mayor, de modo que solo 1 de cada 5 acusados del delito es absuelto.

Repárese también que en muchos casos la sentencia que condenaba a la pena capital del convicto llevaba a pie del texto una recomendación de clemencia al monarca para el reo que no hubiese reincidido y hubiese prestado aval de buena conducta con testigos de crédito, o cuando concurrían circunstancias de carácter personal del reo ${ }^{129}$. Sin embargo, la clemencia real para los más desfavorecidos en muy contados casos se concedía por la presión de las clases más pudientes para utilizar la pena como escarmiento y disuasión del delito ${ }^{130}$.

Desde 1835 el TCPL no dicta sentencia de castigos corporales ni de pena de muerte por falsificación documental. Siguiendo la prescripción legal, este Tribunal impone pena de deportación durante 15 años para la falsificación cualificada y de 10 años para el cooperador necesario ${ }^{131}$. A partir de 1862 desaparece también la pena de deportación para el delito de falsedad documental, ocupando su lugar la prisión perpetua (penal servitude for life), que acaba también reduciéndose en 1875 a siete años y a partir de 1900 a tres años.

\section{CONCLUSIONES}

i.- El instituto del crimen falsi no tuvo amparo legislativo hasta el s. XV en los territorios ingleses. Los códigos de los monarcas anglosajones del Altomedievo solo prevén la adulteración del sello regio, que se castiga con pena capital por integrarse esta conducta entre los actos de alta traición. Los derechos, privilegios o acuerdos entre particulares, las reclamaciones de obligaciones contraídas se acreditaban en juicio por medio de testigos de parte o cojuradores (oath-helpers). La prueba documental era prácticamente inexistente en

\footnotetext{
129 OBP, June 1720, trial of John Hunt (t17200602-39).

130 MCGOWAN (1999) p. 137 o SMITH (2005) pp. 23-41.

131 OBP, September 1843, trial of Edward Hemingway, John David Burgess (t18430918-2625)]. En cambio, solo se dicta la pena de prisión a partir de 1862, por ejemplo, a William Roupell en 1862 [OBP, September 1862, trial of William Roupell (t18620922-1015)]. A partir de 1885 la pena de prisión se reduce a 7 años; castigo que el TPCL impuso Samuel Morgan en 1889 [OBP, February 1889, trial of Samuel Morgan (t18890204246)] y finalmente la pena disminuye a tres años a partir 1900.
} 
el Altomedievo anglosajón. Tras la instauración del instituto del jurado en el Bajomedievo, con funciones instructoras y juzgadoras de los hechos, los testigos de parte quedan relegados del juicio oral, de modo que empieza a darse importancia a la prueba documental. Sin embargo el Common Law del Bajomedievo no dispone de títulos de punición para sancionar el "delito" de falsedad documental, pues sigue sin configurarse la noción de crimen falsi, que no se recoge ni en Britton ni tampoco lo contempla Bracton, limitándose el Common Law y la legislación penal (Statute of Treason de 1351) a sancionar el Great and Privy Seal del rey como uno de los siete tipos de traición contra la Corona.

ii.- En cambio, en los territorios hispánicos, el delito de falsedad documental tiene un profundo arraigo normativo ya en la época visigoda que arranca de la Lex Cornelia y de su desarrollo doctrinal por los jurisconsultos del Bajo Imperio. El Liber Iudiciorum diseña los dos elementos básicos constitutivos del delito de falsedad documental que vienen a sintetizarse como un acto consciente (que puede adoptar múltiples formas de ejecución, de ahí la amplitud del objeto material del delito) de "mudamiento" de la verdad realizado con dolo en beneficio propio o por malquerencia. Estas notas distintivas se reproducen en general en muchos ordenamientos municipales y territoriales extensos del período Bajomedieval. Así pues, a diferencia de los territorios ingleses, la legislación local y la territorial extensa hispánica diseñó el instituto del crimen falsi relativo a la falsificación de documentos con una variada tipología de penas, dependiendo del grado de romanización de los textos normativos.

iii.- Es significativo, no obstante, que tanto en los territorios ingleses como hispánicos (en general, en todos los territorios de la cristiandad) en el período Bajomedieval se produce una extensa actividad "falsificadora" en los propios scriptoria eclesiásticos, bien sea para dar mayor legitimidad a derechos y privilegios adquiridos o, simplemente para arrogárselos ilegítimamente. La prueba documental empieza a tener prevalencia en los juicios y los actores se afanan en presentar documentos espurios o de dudosa veracidad. Considerando que apenas existía persecución de oficio, la parte agraviada se limitaba, cuando aducía falsedad documental de contrario, a recuperar el derecho arrebatado o lesionado, más que el castigo del falsario. Por eso, los casos en los que se comprueba aportación de documento falso, el juzgador puede limitarse exclusivamente, en algunas jurisdicciones territoriales, a que el falsario pierda la causa, sin ulterior castigo del falsario.

iv.- En el ámbito inglés, a diferencia de los ordenamientos hispánicos, el Statute Against Forgers of false Deeds de 1413 (primer texto normativo en sancionar la falsificación de documentos privados) proporciona a la parte perjudicada -por uso de documento falso de contrario- no solo la correspondiente acción reivindicatoria de propiedad o dominio, sino también una acción civil por daños y perjuicios contra aquellos que forged and proclaimed any false deeds y para los que entorpecían el disfrute del título o la posesión con documentos falsos. Bien es cierto que esta ley tiene escasa efectividad porque solo se podía incoar proceso a instancia de parte con el riesgo de que el actor asumía un elevado coste, si no se probaba la falsedad. El Statute of Forgery de 1563 presenta un diseño más amplio de las conductas delictivas y un mayor rigor punitivo. Se motiva su promulgación por la creciente importancia de los documentos y por la inseguridad jurídica que surge de su frágil vulnerabilidad afectando principalmente a derechos de posesión y transmisión de títulos de propiedad y a instrumentos comerciales y financieros que operaban en el tráfico jurídico 
mercantil. No obstante, la calificación del delito sigue como misdemeanour aunque con una considerable sanción (confiscación, picota e infamia).

v.- En los territorios hispánicos de la Modernidad temprana, el régimen sancionador sigue siendo básicamente el de las Partidas en los territorios en los que irradia su influencia el Derecho territorial castellano, de modo que el que falsificase bula, firma o sello del Papa o del monarca incurría en pena de muerte, mientras que el que incurriese en falsificación de escrituras privadas en perjuicio ajeno era condenado a la pena de destierro y confiscación de bienes, junto con la pérdida del litigio en causa civil. Considerando que en más de la mitad de las causas (según se desprende de los juicios que he observado en la Real Audiencia y Chancillería de Valladolid) se acusa a escribano público de autor de la falsedad, para el que se prescribe amputación de mano, y, tras la Pragmática de Felipe II en 1566, vergüenza pública y galeras, lo cierto es que los escribanos se libraban con el pago de una multa y suspensión temporal de oficio.

vi.- En el ámbito inglés, el Statute (2 Geo. 2. c. 25) de 1729 produce un cambio radical en el régimen sancionador, pues la falsificación de documento privado destinado al tráfico jurídico, especialmente todo instrumento del mercado financiero (cheques, pagarés, letras de cambio, endosos, etc.) y otros instrumentos relativos a la transmisión de derechos y bienes (testamentos, cesión de derechos, exoneración de deuda, etc.) se contempla como una felonía. La práctica forense del TPCL así lo corrobora, bien es cierto que ante el rigor de la ley, la mayoría de los encausados quedaban absueltos, pues los convictos iban irremisiblemente a la horca.

vii.- En cambio, en la Modernidad tardía hispánica el delito de falsedad en documento privado apenas tiene un reflejo judicial, la mayoría de los casos incluidos los escribanos falsarios acaban impunes por falta de pruebas o con simples sanciones pecuniarias de carácter discrecional.

\section{BIBLIOGRAFÍA CITADA}

Alejandre García, Juan Antonio (1972): "Estudio histórico del delito de falsedad documental", Anuario de Historia del Derecho Español, vol. XLII: pp. 117-187.

Álvarez Posadilla, Juan (1833): Comentarios a las Leyes de Toro según su Espiritu y el de la Legislación de España (Madrid, Imprenta que fue de Fuentenebro).

Álvarez-Coca González, Ma Jesús (1987): "La figura del escribano", Boletín de la ANA$B A D$, vol. XXXVII: pp. 555-564.

Azcárate Aguilar-Amat, Pilar et al. (2006): "Volver a nacer: historia e identidad en los monasterios de Arlanza, San Millán y Silos (siglos xii-xiii)", Cahiers d'Études Hispaniques Medievales, vol. XXIX: pp. 359-394.

Barrau-Dihigo, Lucien, (1900): "Chartes de l'Église de Valpuesta du IX au XI siècle", Revue Hispanique, vol. VII: pp. 274-293.

Berní i Català, Joseph (1749): Práctica Criminal con nota de los delitos, sus penas, presunciones y circunstancias que los agravan, y disminuyen; $y$ ritual para juzgar, acriminar, y defender en los tribunales reales de España, y en los particulares de residencias (Valencia, Acosta de Simon Faure). 
Binding, Karl (1904): Lehrbuch des Gemeinen Deutschen Strafrechts, Tomo II (Leipzig, W. Engelman, segunda edición).

Blackstone, William (1765-1769): Commentaries on the Laws of England, Tomo IV (Oxford, Clarendon Press).

Bracton, Henry de (1922): De Legibus et Consuetudinibus Angliae, en Woodbine, George E. (edit.), (New Haven, Yale University Press, $1^{a}$ edición 1569; tratado escrito $c$. 1235)

BRETT, Martin (1988): "Forgery at Rochester", en Fälschungen im Mittelalter, Internationaler Kongress der Monumenta Germaniae Historica, vol IV: pp. 397-412.

Britton (1640): en Wingate, Edmund (edit), (London, printed by the assignes of John Moore, segunda edición).

Brooke, Christopher N.L. (1962): "Episcopal Charters for Wix Priory”, en Barnes, Patricia M. y Slade, Cecile F. (edit.), A Medieval Miscellany for Doris Mary Stenton, Tomo NS XXXVI (London, The publications of the Pipe Roll Society) pp. 45-63.

Brooke, Christopher N.L. (1971): "Approaches to medieval forgery", en Brooke, Christopher N.L. (edit.), Medieval Church and Society: Collected Essays (London, Sidgwick and Jackson) pp. 100-120.

Cancer, Jacob (1683): Variarum resolutionum juris Caesarei, Pontificii et Municipalis Principatus Cathalauniae, Tomo I (Lugduni, sumptibus Petri Borde, Joannis [et] Petri Arnaud).

Cantera Montenegro, Margarita (2013): "Falsificación de documentación monástica en la Edad Media: Santa María de Nájera", Espacio, Tiempo y Forma, Serie III, H.a Medieval, vol. XXVI: pp. 59-76.

Carnelutti, Francesco (1935): Teoría del falso (Padua, Cedam).

CASTILlo Sotomayor, Juan del (1686): Repertorium generale rerum notabiliorum seu materiarum omnium (Lugduni, apud Anissonios, Joan Posuel [et] Claud. Rigaud).

Chaplais, Pierre (1962): "The original charters of Herbert and Gervase Abbots of Westminster (1121-1151”, en Barnes, Patricia M. y Slade, Cecile F. (edit.), A Medieval Miscellany for Doris Mary Stenton (London, Pipe Roll Society).

Chibnall, Marjorie (1986): "Forgery in narrative charters", en Fälschungen im Mittelalter, Internationaler Kongress der Monumenta Germaniae Historica, vol. IV: pp. 331-346.

Clanchy, Michael (1979): From Memory to Written Record England 1066-1307 (London, Blackwell).

COKE, Sir Edward (1680): Institutes of the Laws of England (London, Imprenta de W. Rowlins)

Dickens, Charles (1997): “Night walks', All the Year Round, 21 July, 1860”, en PAscoe, David (edit.), Selected Journalism 1850-1870 (London, Penguin).

Escalona Monge, Julio et al. (2002): "De la crítica diplomática a la ideología política. Los diplomas fundacionales de San Pedro de Arlanza y la construcción de una identidad para la Castilla medieval", Actas del VI Congreso Internacional de Historia de la Cultura Escrita Tomo II (Alcalá de Henares, Universidad de Alcalá de Henares) pp. 159-206.

Escalona Monge, Julio (2004): "Lucha política y escritura: falsedad y autenticidad documental en el conflicto entre el monasterio de Santo Domingo y el burgo de Silos (siglos XIII-XIV)", en Iglesia Duarte, José I. de la, Conflictos sociales, politicos e intelectuales en la España de los siglos XIV y XV (Logroño, Instituto de Estudios Riojanos) pp. 205-252. 
Extremera Extremera, Miguel Á. (2001): “ Los escribanos de Castilla en la Edad Moderna. Nuevas líneas de investigación", Chronica Nova, vol. XXVIII: pp. 159-184.

Extremera Extremera, Miguel Ángel (2005): "El delito en el archivo. De escribanos, falseadores y otras gentes de mal vivir en la Castilla del Antiguo Régimen”, Hispania, vol. LXV, No 2: pp. 465-484;

Farinaccio, Próspero (1631-1635): Praxis et theoricae criminalis, Tomos I-IV (Lugduni, Sumptibus Iacobi Cardon).

Filangieri, Gaetano (1796): La scienza della legislazione, 2. ${ }^{\mathrm{a}}$ ed. (Venezia, Giacomo Storti). Fleta (1955, 1972 y 1982): en Richardson, Henry G. y Sayles, George O. (edit), Tomos I-IV) y SaYles, George O. (edit.), Tomos V-VI) (London, Selden Society).

Fontanella, Juan Pedro (1622): De pactis nuptialibus sive Capitulis matrimonialibus tractatus: multis regiae andientiae principatus Cathaloniae (Barcelona, apud Germanum Nanty \& soc.).

Fontanella, Juan Pedro (1668): Decisiones Sacri regii senatus Cathaloniae (Lugduni, apud Germanum Nanty \& soc).

García de Cortázar y Ruiz de Aguirre, José Á. (2003): “Monasterios castellanos, memoria histórica y organización de la sociedad y del espacio en los siglos x al xii", en Silos. Un Milenio. Actas del congreso sobre la Abadía de Santo Domingo de Silos. vol. II (Burgos, Universidad de Burgos) pp. 143-176.

García de Cortázar y Ruiz de Aguirre, José Ángel (2005): "La construcción de memoria histórica en el monasterio de San Millán de la Cogolla (1090-1240), en Cordero RiveRA, Juan (edit.), Los monasterios riojanos en la Edad Media: historia cultura y arte (Logroño, Ateneo Riojano) pp. 69-92.

Glanvill, Ranulph de (1780): Tractatus de legibus et consuetudinibus regni Anglie (London, Imprenta de J. White et E. Brooke, tercera edición).

GonZÁlez de Amezúa, Agustín (1953): "Apuntes sobre la vida escríbanil en los siglos XVI al XVIII”, Opúsculos histórico-literarios, vol III: pp. 279-307.

HiatT, Alfred (2004): The Making of Medieval Forgeries: False documents in Fifteenth-Century England (Toronto, University of Toronto Press).

HoldsworTh, William (1903-1966): History of English Law, Tomos I-XVII (London, Methuen and Co).

IbáÑez García, Miguel Ángel (2003): "El Privilegio' de Alfonso II: introducción al señorío de Valpuesta en los siglos XI-XII", Sancho el Sabio, vol XVIII: pp. 151-174.

IZIAR, Juan de (1550): Arte subtilisima por la cual se enseña á escrevir perfectamente hecha, experimentada y agora de nuevo añadido (Zaragoza, Casa de Pedro Bermuz).

López de Salcedo, Ignacio (1666): Practica criminalis canonicae (Maguncia).

López, Gregorio (1844): Las Siete Partidas del Sabio Rey D. Alfonso IX (Barcelona, Imprenta de Antonio Bergnes).

Lот, Ferdinand (1898): "Nouvelles études sur la provenance du cycle arthurien: I. Glastonbury et Avalon", Romania, vol XXVII: pp. 529-73.

Martínez Gijón, José (1962): "Estudios sobre el oficio de escribano en Castilla durante la Edad Moderna”, en Centenario de la Ley del Notariado, Tomo I (Madrid, Editorial Reus) 
MatTheu y Sanz, Laurentii (1686): Tractatus de re criminali sive controversiarum (Lugduni, Apud fratres Anissonios, Ioann. Posuel \& Claudium Rigaud).

Mayer Lux, Laura y Vera Vega, Jaime (2015): "Historia del objeto material del delito de falsedad documental punible", Revista de Estudios Histórico-Jurídicos, vol. XXXVII: pp. 325-346.

MCGOWAN, Randall (1999): "From pillory to gallows: the punishment of forgery in the age of the finantial revolution", Past and Present, vol XLV: pp. 107-140.

McGowan, Randall (2002): "Forgery Legislation in Eighteenth-Century England", en Landau, Norma (edit.) Law, Crime, and English Society 1660-1830 (Cambridge, Cambridge University Press).

Mieres, Thomam (1621): Apparatus super constitutionibus curiarum generalium Cathaloniae (Barcelona, typis, [et] aere Sebastiani a Cormellas).

Ortego Gil, Pedro (1998): "La pena de vergüenza pública (siglos XVI-XVIII). Teoría legal castellana y práctica judicial gallega", Anuario de Derecho Penal y Ciencias Penales, vol LI: pp. 153-204.

Pearsall, Derek (2003): "Forging truth in medieval England", en RYan, Judith y Thomas, Alfred (edit.), Cultures of Forgery. Making Nations, Making selves (Nueva York, Psychology Press).

Peña Pérez, Francisco Javier (2003): "Los monjes de San Pedro de Cardeña y el mito del Cid”, en Iglesia Duarte, José I. de la (edit.), Memoria, mito y realidad en la Historia medieval, vol. XIII (Logroño, Instituto de Estudios Riojanos) pp. 331-344.

Peña, Antonio de la (1934-1936): Tratado muy provechoso, útil y necesario de los jueces y orden de los juicios y penas criminales, en López-Rey y Arrojo, Manuel (edit.), "Un práctico castellano del siglo XVI", Revista de Ciencias Juridicas y Sociales, vol. XVII, No 69: pp. 655-802 y vol XVIII, No 70: pp. 149-203.

Pollock, Frederick y Maitland, Frederic W. (1968): the History of English Law (Cambridge, Cambridge University Press, segunda edición).

RamSAY, Nigel (1991): "Scriveners and Notaries as legal intermediaries in Later Medieval England", en Kermode, Jennifer (edit.), Interprise and Individuals in Fifteenth-Century England (London, Sutton Publishing Ltd).

Razón del juicio seguido en la ciudad de Granada (Chancillería de Granada) contra varios falsificadores de escrituras públicas, monumentos sagrados, y profanos, caracteres, tradiciones, reliquias, y libros de supuesta antigüedad (1981) (Madrid, Imprenta de Joaquín Ibarra).

Scammell, Geoffrey V. (1956): Hugh du Puisset: Bishop of Durham (Cambridge, Cambridge University Press).

SESSE, José de (1615): Decisionum sacri senatus regii regni Aragonum et curiae domini, (apud Ioannem à Lanaja \& Quartanet).

Sharpe, James A. (1999): Crime in Early Modern England 1550-1750 (London, Longman Publishing, segunda edición).

SMITH, Hannah (2005): "The court in England, 1714-1760: a Declining Political Institution?” History, vol. XC: pp. 23-41.

Southern, Richard W. (1958): “The Canterbury forgeries”, English Historical Review, vol. LXXIII: pp.193-226. 
IGLESIAS RÁBADE, Luis —studio comparado del delito de falsedad documental en el derecho hispánico e inglés (siglos XVI-XVIII)

Stenton, Frank Merry (1925-1926): “The Free Peasantry of the Northern Danelaw”, Bulletin de la Société Royale des Lettres de Lund, vol. CI-CII: pp. 73-185.

Stephen, James Fitzjames (2014): A History of the Criminal Law of England (Cambridge: Cambridge University Press, impresión digital de la primera edición de 1883).

TouT, Thomas Frederick (1920): "Medieval Forgers and Forgeries", Bulletin of the John Rylands Library, vol. V: pp. 208-234.

Vela y ACuña, Juan (1603): Tractatus de poenis delictorum quem Salmanticae auditoribus suis dictabat licentiatus don Ioannes Vela \& Acuña diui Bartholomaei collega \& cathedra voluminis publico stipendio praefectus (Salamanca). 